\title{
An Idea Model for Distributed Idea Management
}

\author{
Heiko Duin ${ }^{1}$, Roxana Belecheanu ${ }^{2}$, Luis Oliva ${ }^{3}$, Klaus-Dieter Thoben ${ }^{1}$ \\ ${ }^{1}$ BIBA - Institut für Produktion und Logistik GmbH, Hochschulring 20, D-28359 Bremen, Germany, \\ \{du, tho\}@biba.uni-bremen.de \\ ${ }^{2}$ SAP Research CEC Belfast, The Concourse, Queen's Road, BT3 9DT Belfast, UK, \\ roxana.belecheanu@sap.com \\ ${ }^{3}$ Departament de Llenguatges i Sistemes Informàtics (LSI), Universitat Politècnica de Catalunya (UPC), \\ Campus Nord, Edif. Omega, C. Jordi Girona, 1-3, 08034 Barcelona, Spain, loliva@lsi.upc.edu
}

\begin{abstract}
Processes of Open Innovation and innovation in Living-Labs applying the co-creation paradigm do involve many participating innovators across different organisations and stakeholder groups. This is especially true when dealing with disruptive or radical innovations instead of incremental ones. Any methodology and/or tools supporting such processes are distributed and need to be able to transfer knowledge artefacts such as ideas from one application to another. This paper describes how a repository storing ideas has to be organised in order to address the most important requirements coming from the tasks of creating and evaluating ideas. A model is presented which can be implemented using Internet standards like REST.
\end{abstract}

\section{Keywords}

Open Innovation, Living-Labs, Ideation, Creativity, Idea Model

\section{Introduction}

In the global market, with the emergent economies, European enterprises have serious difficulties in surviving, let alone excelling, unless they are capable to leverage successfully their capacity to innovate. Enterprises in almost all sectors are forced to develop innovative products in shorter cycles due to market constraints. In this context, Wang and Ahmed (2003) describe the market situation as dominated by hyper-dynamics, uncertainty and chaos.

The innovation statistics carried out with European enterprises demonstrates a paradox in Europe of having good research activities, but with poor impact concerning innovation and global competitiveness (EIS, 2009). This raises significant challenges concerning the implementation of the Lisbon strategy to transform the EU into the "most competitive and dynamic knowledgebased economy in the world, capable of sustainable economic growth with more and better jobs and great social cohesion" (EurActiv, 2000) where innovation plays a fundamental role. The problem is not necessarily lack of funding, with the EU RTD programme totalling 229 billion Euros in 2007, neither is it lack of engagement of enterprises in innovation, with $41.2 \%$ in industry and 36\% in services (Parvan, 2009). However, the reality demonstrates that a total 85\% of product development resources are wasted on products and services that never reach the market, which is compounded by the fact that only $18 \%$ of those products reaching the market actually prove successful (Bauer, 2005; INA, 2005). In addition, the distribution of innovation across Europe is uneven, with Sweden, Finland, Germany, Denmark and the UK considered as innovation leaders in the European Innovation Scoreboard (EIS) in 2008 (EIS, 2009). 


\section{Relation to Existing Work}

\subsection{General Placement}

In response to the pressures resulting from competing in a global market, enterprises follow two major trends:

- Open Innovation. The limitations of the internally focused innovation are summarily captured in the simple simulation of Red Queen Effect (Bayless, 2009) applied to product development. The simulation indicates that a $10 \%$ decrease in product life cycle would require a company to double the introduction of new sustainable products each year, which implies significant increases in innovation funding just to maintain for the company to keep its market position. This is a simple simulation based on shrinkage of the product lifecycle. If one considers the globalisation phenomenon, then it is unthinkable to keep the closed innovation model. Consequently, organizations have been compelled to reach out beyond their boundaries to engage with others in the attempt of maximising the efficiency of their innovation processes by collaborating with others. The realization that the world no longer allows for companies functioning in isolation has led to the establishment of a networked fabric composed of enterprises collaborating with one another based on a platform of trust - Collaborative Networked Organizations (Camarinha-Matos, 2008).

- Extended Products. Facilitated by the paradigm of sustainable development, enterprises have realized that their customers are more interested in solutions to a need, rather than a packaged product. This introduces the concept of extended products, where a product is enriched with services and the business model is focused on what needs are addressed by the combined solution (e.g. Jansson and Thoben, 2005). So for example, one may consider that car manufacturers are moving away from providing a simple car towards providing a solution for mobility.

These trends have a significant impact on the way innovation has been traditionally viewed and dealt with by enterprises, which no longer consider it viable to harness alone the necessary creativity power within their corporate boundaries to excel. Consequently, the barriers of closed innovation have been torn down and the new paradigm of Open Innovation (Chesbrough, 2003) has been adopted, where multiple parties are engaged thus increasing the creativity potential.

Initially the paradigm of open innovation was applied solely to the enterprises, but the open innovation movement has gone even further than organizational boundaries reaching out towards individuals, realizing that the global connectivity provided by the Internet has created something like a Global Brain. This has led to the notions of crowd sourcing, but there are multiple challenges towards harnessing successfully the power of the masses and the success cases are more anecdotal rather than systematic.

A harsh reality concerning innovation is the low success rate of transforming ideas into sustainable business models, and in response, the Living Lab paradigm (Schumacher and Niitamo, 2008) has emerged where the creation process is not only open involving multiple innovators, but places the customer at the centre of the innovation process, actively taking part of the creation of products and services at every step. However, the novelty of Living Labs implies that there are serious challenges for individuals and organisations to adopt the paradigm to produce successful outcomes.

\subsection{The Early Phase of Innovation}

The very beginning of an innovation process - often called the fuzzy front end to innovation (Williams et al., 2007) - is characterised by ideation, idea refinement, knowledge creation, evaluation, verification, etc. Often, these steps do not follow a linear approach, but are rather unorganised, following an unpredictable circular way (Duin et al., 2008b). The remainder of this 
paper assumes such activities in an inter-organisational setup which is called Collaborative Innovation.

\subsection{Collaborative Innovation}

Collaborative Innovation is performed by "a cyberteam of self-motivated people with a collective vision, enabled by the Web to collaborate in achieving a common goal by sharing ideas, information, and work" (Gloor, 2006, p. 4). This definition by Peter Gloor exactly describes what happens in the fuzzy front end to innovation.

Clearly, there is a need to manage and maintain ideas and information during that early phase of distributed and open innovation processes by providing a coherent idea model where all involved applications can adhere to.

\subsection{Idea Modelling}

The term idea is quite common in philosophy related to all languages and periods. One of the historical views of an idea is that ideas exist in a realm which is separate from our real life. This view states that we discover ideas in the same way that we discover the real world. Three examples from philosophy are:

- Plato claimed that there is an area consisting of forms or ideas, which exists independently of anyone who may have thought of these ideas. Material things are imperfect and transient reflections or instantiations of the perfect and unchanging ideas (Ross, 1956).

- Descartes understood an idea as an image or representation which is in the mind. In his Meditations on First Philosophy he claims that some of his thoughts are like images of things, and it is to these alone that the name idea properly belongs to (Cottingham, 1996).

- Locke defines an idea as being that term which serves best to stand for whatsoever is the object of the understanding when a man thinks. He used it to express whatever is meant by phantasm, notion, species, or whatever it is which the mind can be employed about in thinking (Jolley, 1999).

In modern times, most people agree that an idea is an image existing or emerging in the mind. Ideas give rise to concepts, which are the basis for knowledge in areas like science or business. Concepts can support the integration of apparently unrelated characteristics or phenomena into viable assumptions and theories, which are the basic building blocks of new and innovative products or services. Evaluations do help to shape concepts and to determine idea exclusivity and validity.

Idea Management systems are software solutions to support the ideation phase in innovation projects. The company Capterra is running an online software repository which lists about 45 solutions for idea management (see http://www.capterra.com/idea-management-software). Most of these solutions are still targeting the own employees as the ideation resources, only a few of them also include suppliers and/or customers. Most of these solutions are based on a specific approach (e.g. prediction markets) to gather and evaluate ideas and do not provide interfaces to other applications.

Most of the current solutions are lacking accessibility from outside the organisation in a controlled way which makes them useless for Open Innovation processes. Another missing feature is the non-existence of exchange formats for transferring set of ideas from one application to another.

\section{Research Approach}

The idea generation - or ideation - process is the starting point of each innovation process before it concludes into one of the well known stage-gate processes. The European Integration Project 
(IP) Laboranova develops an Internet-based toolset supporting the collaborative generation, management and evaluation of ideas (Duin et al., 2008a). In total, more than 20 approaches and tools have been considered supporting the connection of experts, ideation and evaluation of ideas in that early phase, including approaches such as:

- Distributed Brainstorming

- Collaborative Exploration

- Serious Gaming

- Prediction Markets

- Advanced Evaluation

Each of the developer partners of Laboranova has performed an own requirements analysis with involved end-users to back-up the specification and implementation of their specific approaches. A common analysis and compilation of each of these requirements provides the common ground for the Laboranova idea model which is implemented as an underlying idea repository accessible for each of the tools.

\section{The Laboranova Idea Model}

\subsection{Basic Requirements for the Idea Model}

The main goal for the underlying idea repository is to maintain the semantics of information while exchanging of data among tools. Therefore, this model also acts as a kind of ontology for the participating tools. Ideas are running through a life cycle. They are created, commented, tagged, rated, grouped, modified, evaluated, etc. Any change to an idea needs to be reflected by the model. Finally, the model should provide means to allow a structured access to information in order to support any ownership and/or IPR issues on ideas.

Further, quite specific requirements are:

- Ideas vs Concepts: When ideas are maturing during the early phase they should represent a concept, which is an artefact to be used as the starting input for new product development process. Several ideas can be combined into a concept and a specific idea may be part of several concepts.

- Idea Groups: Ideas can be grouped into groups, and groups can be further sub-divided into sub-groups, etc. This represents a hierarchical element for structuring ideas in an idea tree.

- Tagging: Any kind of tags associated to an idea and provided by an end user should be stored.

- Attachments: Any kind of attachment (text, diagram, audio, video, etc.) associated to an idea should be stored.

- Ratings: When a set of ideas was subject to a rating the result of that rating should be stored with the ideas.

- Evaluations: When a set of ideas was subject to an evaluation the result of that evaluation should be stored with the ideas.

- Comments: Any comment provided by an user of the idea repository should be stored with the respective idea.

- Forum: Ideas can be subject to discussions. Typically, discussions are performed in Web-based forums. Therefore, the relation of any postings to a forum and the concerned idea should be stored. 
- Organisations and users: They must be explicitly modelled to ensure an effective IPR management.

- Competences: Together with the users, competence profiles should be stored for two reasons: First, this makes it easier to assess comments, ratings, etc. from specific users when their competences are known, and second, this allows the search for competent users to be involved in ratings and evaluations.

\subsection{The Idea Model}

The above Figure 1 shows the Laboranova idea model as a class diagram. The core entity is the idea class which has - besides the key attributes id and creation date - the following attributes:

- Updated: a timestamp which stores the date of the last modification of an idea. Once the idea versioning system works, this will be a capital field, since it will be used to distinguish different versions of the same idea (not only its fields, but also any element related to an idea would be traced according to this field and the creation field of the elements related to it),

- Link: a URL that links to an external resource (e.g. video, document, sound) and which represents the idea. This is not an attachment (the former is the idea itself, the latter is a way to enrich an idea),

- Abstract: summary of what the idea is,

- Visibility: is it a private or public idea ('private', 'public'),

- Idea_status: in which stage of the innovation process the idea is ('proposed', 'validated', 'accepted', 'implemented', 'draft', 'evaluated', 'submitted', 'under evaluation', 'approved', 'rejected', 'in prototype', 'concept proved', 'abandoned', 'in transfer to production', 'under development'),

- Is_locked: a Boolean value to prevent any further modification.

Ideas relate with the following elements:

- Tags: through 'Ideas_tags'; an idea can be tagged with many tags,

- Attachments: through 'Attachments_ideas'; an idea can have many attachments to enrich it,

- Idea_groups: through 'Ideas_idea_groups'; an idea can be grouped to many groups,

- Ideas: through 'Idea_relations'; an idea can be related with many other ideas,

- Projects: through 'Ideas_projects'; an idea can be used in several different projects,

- Concepts: through 'Concepts_ideas'; an idea can have many concepts for a better understanding,

- Users

o through 'Ideas_creators': an idea can have one or many creators,

o through 'Ideas_viewers': an idea can be seen by many users,

- Ratings: through 'Idea_rating'; an idea can receive many ratings,

- Comments: through 'Comments_ideas'; an idea can have several comments about it (resulting in some sort of discussion),

- Social_entites: through 'Ideas_owners'; an idea has one or many owners which can be users, Social_groups or organisations (usually the latter).

The second major entity is represented as the user class. This element also inherits the fields from its super-class 'Social_entities' and additionally has the following attributes:

- User_profile_id: identifier to retrieve the information from Sharepoint, 


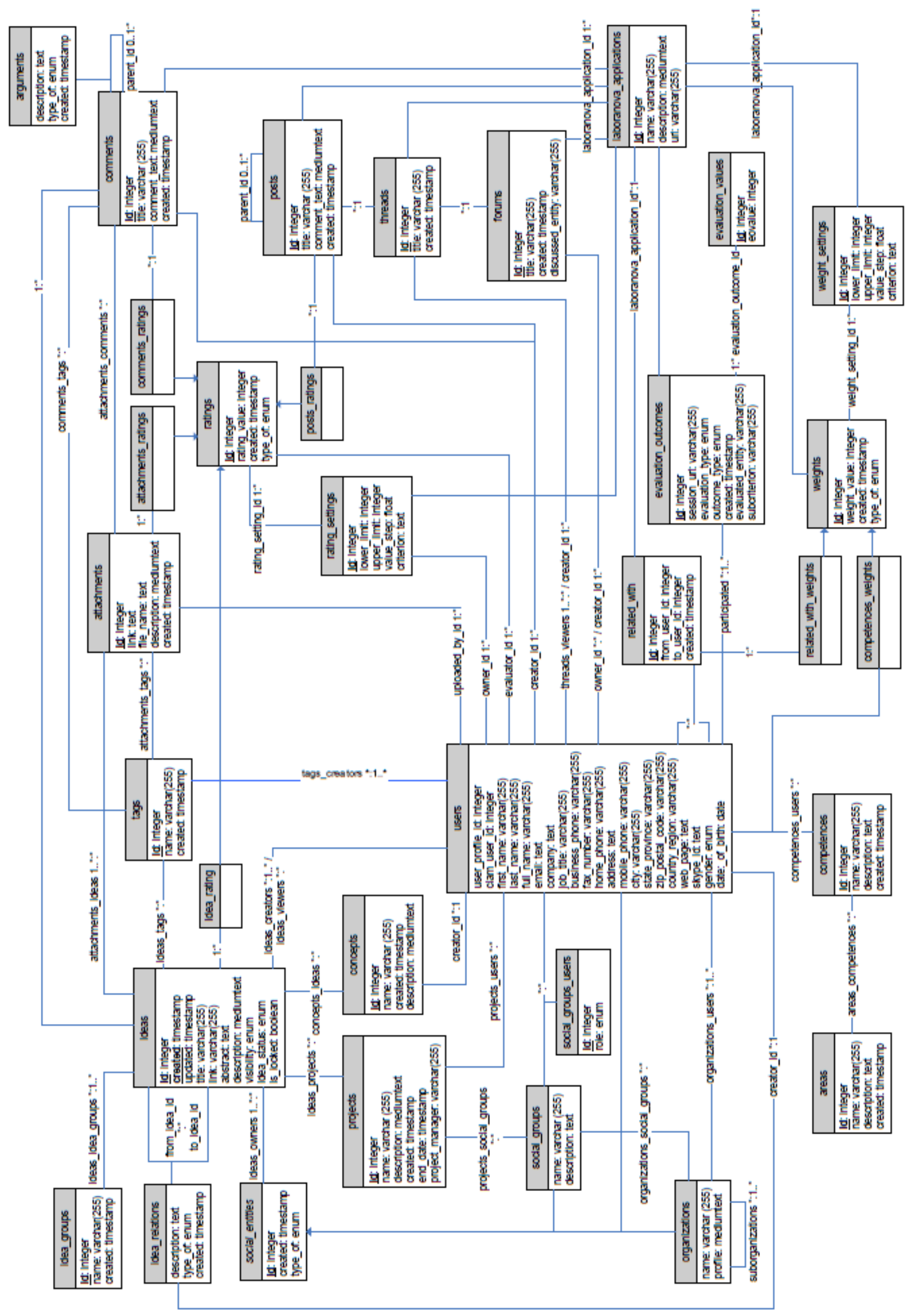

Figure 1: The Laboranova Idea Model as Class Diagram 
- Clam_user_id: identifier used internally to retrieve information from the CLAM system,

- First_name, last_name, full_name: fields to store the name and surname of the user,

- Email: the email address of the user,

- Company: where the user works,

- Job_title: his/her job position,

- Business_phone, fax_number, mobile_phone and home_phone: phone numbers to contact the user,

- Address, city, state_province, region_country and postal_code: postal address of the user,

- Skype: username of the Skype service,

- Web_page: URL to its personal web page,

- Gender: male or female,

- Date_of_birth: user's birth date.

Beside others, the user is related with the following elements:

- Attachments: a user can upload many attachments; each attachment contains a foreign key ('Uploaded_by') to know which user uploaded it,

- Ratings: a user can rate a comment, an idea, an attachment or a post; each rating has a foreign key ('Evaluator_id') to know who rated,

- Comments: A user can make comments about an idea (or reply a comment); each comment has a foreign key ('Creator_id') to know who did the comment,

- Posts: a user can discuss in a forum thread creating posts; each post has a foreign key ('Creator_id') to know who did the post, threads: a user can start discussions creating threads in a forum; each thread has a foreign key ('Creator_id') to know who started the discussion (a user can view (or not) threads),

- Forums: a user can create different forums to promote discussion; a forum has a foreign key ('Creator_id') to know who created it. Through 'Owner'/'Moderates' a user can own/moderate different forums.

Due to space restrictions, the description of the model stops here, but the remaining of the diagram should be self-explainable.

\subsection{Technical Implementation}

The idea repository implementing the shown idea model uses the Representational State Transfer (REST) approach. The content is accessed via a RESTful Web API. REST considers Web services as resources, which are used through given representations. The minimal information unit in REST is a resource. Resources are data sources which store the functionalities and the application state of a system. Resources need to be uniquely named to be able to be identified; therefore they need to be addressed through some sort of globally unique identifier (GUID). For example, the idea with $\mathrm{id}=1$ is accessed via

$$
\text { http://<idea-repository-url>/idea/1 }
$$

Retrieval of information is realised in a similar way. E.g. Retrieving id and title of the last five ideas, in compact format (no information with regards their relations with other elements) is done by

http: //<idea-repository-url>/ ideas. $x m l$ ? limit $=5 \&$ sortdesc=updated\&fields=id, title\&compact $=$ true

A full discussion of the technical implementation is given by Oliva and Ceccaroni (2009). 


\section{Conclusions and Future Work}

This paper presented the Laboranova idea model as the core of an idea repository which supports the generation and refinement work on knowledge artefacts like ideas and concepts. Such a repository is important for integrating tools supporting tasks which are typically found in the early phase of innovation projects (e.g. knowledge creation, ideation, expert evaluation).

The idea model has been tested in several single tool approaches, i.e. a specific tool store and retrieve ideas, concepts, etc. to and from the idea repository. Future work includes the application of inter-tool scenarios showing how an idea is generated and further refined using several tools in a pipeline.

\section{Acknowledgement}

This work has been partly funded by the European Commission through the Project Laboranova under contract No. IST-FP6-035262. The authors wish to acknowledge the Commission and all project partners for their support.

\section{References}

Bauer, R.: Kein Bedarf für Plastikräder. In: Freitag. 43 (2005).

Bayless, D., 2009, Innovation, Clockspeed and the Red Queen Effect, Videoblog on WWW,

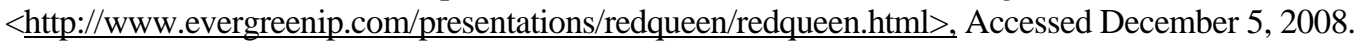

Camarinha-Matos, L. M.: Advances in Collaborative Networked Organisations. In: Innovation in Manufacturing Networks. New York 2008. pp 3-16.

Chesbrough, H. W.: Open Innovation. Harvard Business School Press. Boston 2003.

Cottingham, J.: Meditations on First Philosophy from Rene Descartes. Cambridge University Press. Cambridge 1996.

Duin, H., Geven, A., Dittenberger, S., Tscheligi, M., Hesmer, A. and Thoben, K.-D.: A Toolset to Support the Early Stage of Innovation. In: Proceedings of ERIMA'08 European Symposium on Innovative Management Practices. 2008a. pp 111-118.

Duin, H., Jaskov, J., Hesmer, A. and Thoben, K.-D.: Towards a Framework for Collaborative Innovation. In: Computer Aided Innovation (CAI).IFIP 20th World Computer Congress, Proceedings of the Second Topical Session on Computer-Aided Innovation, WG 5.4/TC 5 Computer-Aided Innovation, September 7-10, 2008, Milano, Italy. Boston 2008b. pp 193-204.

EIS: European Innovation Scoreboard 2008. Comparative Analysis of Innovation Performance. European Commission - Enterprise and Industry. Luxemburg 2009.

EurActiv, 2000, Lisbon Agenda, WWW, <http://www.euractiv.com/en/future-eu/lisbon-agenda/article-117510>, Accessed September 1, 2009.

Gloor, P. A.: Swarm Creativity: Competitive Advantage through Collaborative Innovation Networks. Ocford University Press. Oxford 2006.

INA: Innovation Network Austria Study. 2005.

Jansson, K. and Thoben, K.-D.: The Extended Products Paradigm, An Introduction. In: Arai, E.; Kimura, F.; Goossenaerts, J.; Shirase, K. (Eds.): Knowledge and Skill Chains in Engineering and Manufacturing. Information Infrastructure in the Era of Global Communications. Springer. New York 2005, pp 39-47.

Jolley, N.: Locke: His Philosophical Thought. Oxford University Press. Oxford 1999.

Oliva, L. and Ceccaroni, L.: REST Web Services for Collaborative Work Environments. In: Frontiers in Artificial Intelligence and Applications - Proceeding of the 2009 conference on Artificial Intelligence Research and Development: Proceedings of the 12th International Conference of the Catalan Association for Artificial Intelligence. Amsterdam 2009. pp 419-427.

Parvan, Sergiu: Quality in the Focus of Innovation. In: Eurostat.Statistics in Focus. (2009), pp 1-8.

Ross, D.: Plato's Theory of Ideas. Santa Barbara. Greenwood Press. 1956.

Schumacher, J. and Niitamo, V.-P. (Eds.): European Living Labs. A New Approach for Human Centric Regional Innovation. wvb. 2008.

Wang, Catherine L. and Ahmed, Pervaiz K.: Organisational Learning: A Critical Review. In: The Learning Organization. 10 (2003) 1, pp 8-17.

Williams, M. A., Kochhar, A. K. and Tennant, C.: An Object-oriented Reference Model for the Fuzzy Front End of the New Product Introduction Process. In: International Journal of Advanced Manufacturing Technology. 34 (2007) 7-8, pp 826-841. 